\title{
Ermittlung der Körperschaftsteuerzahllast
}

Zur Ermittlung der (verbleibenden) Körperschaftsteuerzahllast einer Kapitalgesellschaft sind schließlich von der Tarifbelastung bzw. der festzusetzenden Körperschaftsteuer die Körperschaftsteuer-Vorauszahlungen (wie bei der Einkommensteuer sind auch bei der Körperschaftsteuer Vorauszahlungen vorgesehen) und die für Rechnung der Kapitalgesellschaft einbehaltene Kapitalertragsteuer, z. B. auf erhaltene Ausschüttungen, abzuziehen. Die Kapitalertragsteuer als besondere Erhebungsform der Körperschaftsteuer (Quellensteuer) wird hier aus Vereinfachungsgründen vernachlässigt. Hinzuweisen ist lediglich darauf, dass die Kapitalertragsteuer nach $\S 43$ Abs. 1 S. 1 Nr. 1 lit. b EStG auch von Bezügen einbehalten wird, die nach $\S 8$ b Abs. $1 \mathrm{KStG}$ bei der Ermittlung des Einkommens außer Ansatz bleiben.

\section{Vereinfachtes Schema zur Ermittlung der Körperschaftsteuerzahllast:}

Tarifbelastung

$=$ festzusetzende Körperschaftsteuer

./. Körperschaftsteuer-Vorauszahlungen $\S 31$ Abs. 1 KStG i.V.m. § 36 Abs. 2 EStG

= Körperschaftsteuerzahllast bzw. verbleibende Körperschaftsteuer/ggf. Erstattung 